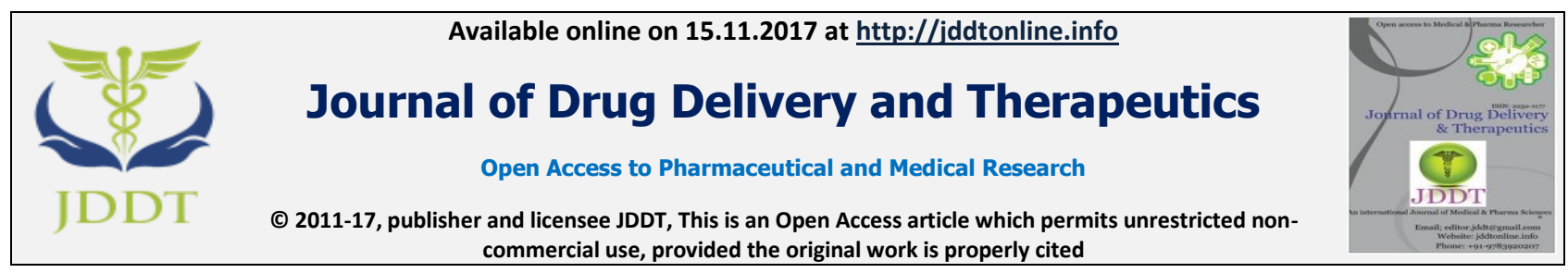

Open $\odot$ Access

Research Article

\title{
FORMULATION AND CHARACTERIZATION OF METFORMIN HYDROCHLORIDE SUSTAINED RELEASE MATRIX TABLET CONTAINING CASSIA TORA MUCILAGE
}

\author{
Chandraprakash Dwivedi ${ }^{1 *}$, S Prakash Rao ${ }^{1}$, Amit Roy ${ }^{1}$, Swarnlata Saraf ${ }^{2}$, Ume kulsum ${ }^{3}$, Nikita \\ Verma $^{2}$, Dusmanta Kumar Pradhan ${ }^{3}$
}

${ }^{1}$ Columbia Institute of Pharmacy, Tekari, Near Vidhansabha Raipur, C.G., 493111, India

${ }^{2}$ University Institute of Pharmacy, Pt. Ravishankar Shukla University Raipur, (C.G.) 492010, India

${ }^{3}$ Apollo College of Pharmacy, Anjora, Durg, Chhattisgarh 491001, India

\section{ABSTRACT}

All the present investigation an attempt has been made to study the formulation and evaluation of matrix tablet of Metformin HCL using natural mucilage of Cassia tora as a release retardant. The matrix tablet was formulated using different drug polymer ratio. The developed formulation of tablet was evaluated for pre-compression and post-compression method. The result of the precompression parameter like Bulk density, tapped density, Carr's index and Hausner's ratio were found to be with the limits indicating good flow properties of the granules. Swelling index reveals that with increasing mucilage concentration there is increased swelling showing $61 \%$ for F-2 at the end of $5 \mathrm{~h}$ where as for F-3 it was around $89.9 \%$ respectively. In- vitro drug release for F3 formulation was found to be $75 \%$ at the end of $10 \mathrm{~h}$. With increases in mucilage concentration the drug release from the matrix tablet got retarded. In- vitro drug release data obtained were fitted to various release model excess the possible mechanism of the drug release. The results of all these parameters are tabulated and depicted graphically in the result and discussion section. IR spectral studies revealed that the drug, polymer and excipients used were compatible. Drug release profile of all formulation was plotted in different kinetics. The calculated regression coefficients showed a higher $r^{2}$ value with higuchi equation $\left(r^{2}=0.958\right)$. Hence the release data of the Tablet obeyed higuchi model and release the drug diffusion.

Keywords: Cassia tora, mucilage, granules, drug release, polymer

Article Info: Received 03 Sep, 2017; Review Completed 17 Oct, 2017; Accepted 05 Nov, 2017; Available online 15 Nov, 2017

口itricle as:

Dwivedi C, Rao SP, Roy A, Sahu D, Verma N, Saraf S, Formulation and characterization of metformin hydrochloride sustained release matrix tablet containing cassia tora mucilage, Journal of Drug Delivery and Therapeutics. 2017; 7(6):66-75

DOI: http://dx.doi.org/10.22270/jddt.v7i6.1520

*Address for Correspondence: Chandraprakash Dwivedi*

${ }^{1}$ Columbia Institute of Pharmacy, Tekari, Near Vidhansabha Raipur, Chhattisgarh, 493111, India.

${ }^{2}$ Apollo College of Pharmacy, Anjora, Durg, Chhattisgarh 491001, India, Email: Chandraprakash9009@gmail.com

\section{INTRODUCTION}

The growing industrial utility of these gums in the field of paper, textile, petroleum recovery and pharmaceutical industries has resulted in an impetus in India for intensified research on new sources of gums and their modified products. Cassia tora mucilage (CTM) derived from the seeds of Cassia tora Linn. Belonging to Caesalpiniaceae is a wild crop and grows in most parts of India as a weed and locally known as charota. A natural gelling agent which has industrial and food applications is made commercially from the seed. ${ }^{1}$ The goal of any drug delivery system is to provide a therapeutic amount of drug to the proper site in the body to achieve promptly and then maintain the desired drug concentration i.e. the drug-delivery system should deliver drug at a rate dictated by the needs of the body over a specified period of treatment. ${ }^{2}$ The two most important aspects of drug-delivery are spatial placement and temporal delivery of a drug. Spatial placement relates to the targeting a drug to a specific organ or 
tissue, while temporal delivery refers to controlling the rate of drug delivery to the target tissue. ${ }^{3,4} \mathrm{An}$ appropriately designed controlled-release drug-delivery system can be a major advance towards solving these two problems Oral route is the most oldest and convenient route for the administration of therapeutic agents because of low cost of therapy and ease of administration leads to higher level of patient compliance. ${ }^{5}$ Sustained drug delivery system was aimed to release the medication in a prolonged rate to maintain plasma drug levels. The drugs having shorter half-life are suitable for the sustained drug delivery system. ${ }^{6,7,8}$ Among the synthetic hydrophilic polymer considered as release retardant but these polymers are quite expensive and biodegradability is question able when compared with natural polymers. Two decades have witnessed a mammoth growth in development of drug delivery systems by using natural gum based matrices. Natural gums are biodegradable and nontoxic, which hydrate and swell on contact with aqueous media, and these have been used for the preparation of dosage form. ${ }^{9,10}$

Drug products designed to reduce the frequency of dosing by modifying the rate of drug absorption are available since many years. Regular research is going on for the use of naturally occurring biocompatible polymeric materials in designing of dosage forms for oral sustained release administration. Among various dosage forms, matrix tablets are widely accepted for oral sustained release (SR) as they are simple and easy formulate. Matrix system is the release system, which prolongs and controls the release of drug that is dissolved or dispersed. In fact, matrix is defined as a well composite of one or more drugs with a gelling agent i.e. hydrophilic polymer. ${ }^{11,12,}{ }^{13}$ Metformin HCL, the only available biguanide, remains the first line drug therapy for patients with type 2 diabetes mellitus acts by decreasing hepatic glucose output and peripheral insulin resistance. It has relatively short plasma half-life, low absolute bioavailability. ${ }^{14,15}$

\section{MATERIALS AND METHODS}

\subsection{Materials}

Cassia tora seeds were collected from the forest of durg, Chhattisgarh, India. Metformin was obtained as gift sample from Active Pharmaceutical Ingredient. All other ingredients were of analytical grade and purchased from Samar chemical and SD Fine-chem Mumbai.

\subsection{Method}

\section{Isolation of mucilage from Cassia tora seeds ${ }^{16,17}$}

The seeds from Cassia were manually cleaned to remove external materials like straw, dust and soil. The damaged and prematured seeds were separated out. The seed were crushed into in mixer. The crushed seed material soaked in water for 5-6 hours, boiled for 30 minutes and left to stand for 1 hour to allow complete release of the mucilage into the water. The mucilage was extracted using a multi-layer muslin cloth bag to remove the marc from the solution. Ethyl alcohol (three times the volume of filtrate) was added to precipitate the mucilage. The mucilage was separated, dried in an oven at $45^{\circ} \mathrm{C}$, collected, ground, passed through a \# 80 sieve and stored in desiccator at $30^{\circ} \mathrm{C}$ and $45 \%$ relative humidity before use. This mucilage was tested for following physicochemical properties. This mucilage was tested for following physicochemical properties. Chemical test, particle size, weight loss on drying, viscosity, ph, density, charring, swelling ratio, bulk density, compressibility percentage, angle of repose, Carr's index. All values were found to be satisfactory.

\subsection{Priminary phytochemical screening of isolated mucilage}

The phytochemical properties such as presence of carbohydrate, protein, flavanoida, sterols, alkaloids, tannins, saponins, fats and terpenoids were determined.

\subsection{Physicochemical properties of dried mucilage}

The physicochemical properties such as solubility, $\mathrm{pH}$, specific gravity and viscosity of dried CTM were determined at $20^{\circ} \mathrm{C}$. The loss on drying, total ash content, acid insoluble ash and water soluble ash were determined according to Ayurvedic Pharmacopoeia of India (A.P.I). ${ }^{18,19}$

\subsection{Identification of drug sample of drug sample by using F.T.I.R:-}

Identification was done by FTIR spectrophotometer .for this small amount of drug sample (Metformin hydrochloride) and FTIR grade potassium bromide $(\mathrm{KBr})$ were triturated in 1:100 ratios. Then required quantity was placed in sample holder and placed in the analytical compartment the sample was scanned for 4000 to $400 \mathrm{~cm}^{-1}$ in spectrophotometer the spectra was match with standard reference spectrum and the principle peaks were matched with reference standard. ${ }^{20}$

\subsection{Drug -excipients compatibility studies:}

Compatibility of excipients with metformin hydrochloride was studied by Fourier Transform Infrared Spectroscopy (Shimadzu). The FT-IR spectra of all combinations containing drug and one or more polymers also show the characteristic peaks same as that of the pure drug. The FT-IR spectrum of all the combinations containing drug and one or more polymer or gum shows same or slightly shift in peak values when compared with the characteristic peak values of pure drug. 21

\subsection{Preparation of calibration curve in 6.8 phosphate buffer:}

\section{Preparation of buffers and reagents:}

PH 6.8 solution of phosphate buffer is prepared as: 250 $\mathrm{ml}$ of $0.2 \mathrm{M}$ Potassium dihydrogen orthophosphate and $112 \mathrm{ml}$ of $0.2 \mathrm{M} \mathrm{NAOH}$ is prepared and taken into 1000 $\mathrm{ml}$ volumetric flask, and then volume up to $1000 \mathrm{ml}$ is adjusted with distilled water and $\mathrm{pH}$ is adjusted at 6.8 using diluted $\mathrm{NAOH}$.

\section{Spectrum of metformin hydrochloride}

From the prepared stock solution, quantity of $0.5 \mathrm{ml}$ is pipette into $100 \mathrm{ml}$ volumetric flask. Using phosphate buffer solution $\mathrm{pH} 6.8$, volume is being made till $100 \mathrm{ml}$. The resulting solution containing $5 \mathrm{ug} / \mathrm{ml}$ was scanned 
between 200 and $400 \mathrm{~nm}$. The $\lambda$ max was found to be $233 \mathrm{~nm}$.

\section{Metformin hydrochloride calibration curve in $\mathbf{p H}$ 6.8 phosphate buffer:-}

Accurately weighed quantity metformin hydrochloride $(50 \mathrm{mg})$ was dissolved in little quantity of phosphate buffer solution $\mathrm{pH}, 6.8$ and volume was made up to 100 ml. appropriate. Appropriate aliquots were taken into different volumetric flasks and made up to $50 \mathrm{ml}$ with $\mathrm{pH}, 6.8$, solution of phosphate buffer so as to get drug concentrations of 2 to $10 \mu \mathrm{g} / \mathrm{ml}$. the blank solution was scanned at 400 to $200 \mathrm{~nm}$, and maximum absorbance was found at $233 \mathrm{~nm}$ and all the absorbance was taken in same wavelength.

Table 1: formulation chart of metformin HCL

\begin{tabular}{|l|l|l|l|l|l|}
\hline S.No & Ingredients (mg) & F1 & F2 & F3 & F4 \\
\hline 1 & Metformin hydrochloride & 200 & 200 & 200 & 200 \\
\hline 2 & Xanthan gum & 20 & 20 & 20 & \\
\hline 3 & Ethyl cellulose & 100 & 100 & 100 & 100 \\
\hline 4 & HPMC & 50 & 50 & 50 & 70 \\
\hline 5 & Microcrystalline cellulose & 80 & 70 & 60 & 80 \\
\hline 6 & Cassia tora & 30 & 40 & 50 & 30 \\
\hline 7 & Isopropyl alcohol & Q.S & Q.S & Q.S & Q.S \\
\hline 8 & Mag-stearate & 10 & 10 & 10 & 10 \\
\hline 9 & Talc & 10 & 10 & 10 & 10 \\
\hline
\end{tabular}

2.9 Preparation of metformin hydrochloride sustained release matrix tablet by wet granulation method:-

\section{Preparation of granules:}

Granules of metformin hydrochloride were prepared by wet granulation technology. All the corresponding powder (metformin hydrochloride, Ethyl cellulose, Xanthan gum, HPMC) were weight individually as per formulation chart then the powder was added in ascending order and mixed with double cone blender for 30 minutes. A soft mass was formed by using CTM paste the wet mass was then passed through a sieve no.22.the prepared granules were then passed through a sieve no.44. Then calculated quantity of talk and magnesium stearate was added as mixed uniformly. These granules were then stored in an air tight container till further processing . ${ }^{22,23}$

\subsection{Evaluation of pre-compression parameter}

Granules prepared by wet granulation technology were evaluated for various rheological properties like bulk density, tapped density, Carr's index, Hausner's ratio and angle of repose by using standard procedure .all these properties were carried out in triplicate $(n=3)$ and average values were reported. ${ }^{24}$

\section{Angle of repose}

Angle of repose is defined as, "the maximum angle possible between the surface of pile of Powder and horizontal plane". The angle of repose for powder of each formulation was determined by the fixed funnel method. A funnel was kept vertically in a stand at a specified height above a paper placed on a horizontal surface. The funnel bottom is closed and $10 \mathrm{gm}$ of sample powder is filled in funnel. Then funnel was opened to release the powder on the paper to form a smooth conical heap, is found by measuring in different direction. The height of the heap was measured by using scale. The value of angle of repose is calculated by using the following formula:

$$
\theta=\tan ^{-1}=\mathrm{h} / \mathrm{r}
$$

Where, h- height of the heap, r-radius of the heap

\section{Tapped density}

Tapped density was determined by placing the granules in a measuring cylinder and the tapped volume $(\mathrm{Vo})$ of granules after 100 tapping's noted the total mass of granules (M) was determined.tapped density was calculated by using the following formula. ${ }^{25}$

\section{Tapped Density $=\mathrm{Vb} / \mathrm{Vf}$}

Where $\mathbf{V b}$ - tapped volume, $\mathbf{V f}$ - final tapped volume

\section{Bulk density}

A known quantity of powder was poured into the measuring cylinder carefully level the powder without compacting, if necessary and read the unsettled apparent volume, V0, to the nearest graduated unit. Calculate the bulk density, in gm per $\mathrm{ml}$, by the formula,

$$
\text { Bulk Density }=\mathrm{m} / \mathrm{V0} \text {, }
$$

Where m - Unsettled, V0 - apparent volume

\section{Compressibility index}

The compressibility Index was calculated by using measured values for bulk density and tapped density as follows:

\section{Compressibility index $=[(\mathrm{Vt}-\mathrm{Vb}) / \mathrm{Vt}] \times \mathbf{x 1 0 0}$}

Where $\mathbf{V t}=$ tapped density, $\mathbf{V b}=$ bulk density

\section{Hausner's ratio:-}

The hausner's ratio was calculated by using measured values for bulk density and tapped

Density as follows:

$$
\text { Hausner Ratio = Dt/Do }
$$

Where Dt $=$ tapped density, Do = bulk density 


\subsection{Evaluation of tablets ${ }^{26,27}$}

\section{Thickness and Diameter:}

Thickness and diameter of tablets was determined using Vernier Caliper. Five tablets from

Each batch was used, \& average values were calculated.

\section{Hardness of the Tablet:}

Tablet hardness has been defined as, "the force required breaking a tablet in a diametric Compression test". For each formulation, the hardness of three tablets was determined using Monsanto hardness tester. The tablet was placed in "Monsanto hardness tester "'.the tablet was placed in Monsanto hardness tester vertically and the force was applied with the help of screw the end point was detected by breaking the tablet.

\section{Weight variation test:}

Twenty tablets were randomly selected and weighed to determine the average weight and were compared with individual tablet weight. The percentage weight variation was calculated as per Indian Pharmacopoeial Specification. Tablets with an average weight more than $400 \mathrm{mg}$ should not be more than $\pm 5 \%$.this is an important process which comes under quality control test according to standard in one batch all tablet should be in uniform weight the weight variation test was performed with the help of digital weighing balance. From the one batch 20 tablets were selected randomly as sample and their individual weight was determined and average weight was determined .finally percentage deviation was calculated by the using following formula:

$$
\% \text { deviation }=\frac{\text { individual weight } \text {-average weight }}{\text { Average weight }} \times 100
$$

\section{Friability test:-}

10 tablets from each batch were selected randomly selected from the batch as a sample and their collectively initial weight was determined.aal the tablet were placed in friabilator and rotated for 100 revolutions at 25 RPM. After rotation final weight was determined. The percentage of friability was calculated by following formula. According to standard the weight loss should not be more than $1 \%$.

Following formula was used to calculate the friability

$$
\mathrm{F}=(1-\mathrm{W} / \mathrm{Wo})_{\times} 100
$$

Where, Wo - Weight of tablet before test. W- Weight of tablet after test.

$$
\% \text { Friability }=\frac{\text { individual weight }- \text { average weight }}{\text { Average weight }} \times 100
$$

\section{Determination of drug content:-}

The drug content of metformin hydrochloride was determined with the help of ph 7.4 phosphate buffer solution .tablets were placed in $100 \mathrm{ml}$ of ph 6.4 phosphate buffer solution individually. It was kept for 24 hours in room temperature and filtered. $1 \mathrm{ml}$. of solution was withdrawn and diluted up to $10 \mathrm{ml}$ with the help of ph 6.4 phosphate buffer solution and absorbance was recorded by UV-Visible spectrophotometer at 233 nm. Finally the drug content was determined by using calibration curve.

\section{6. in -vitro dissolution study:-}

Dissolution study of metformin hydrochloride tablet was performed with the help of united states pharmacopoeia (USP) XXIII dissolution testing apparatus I(basket type ). $900 \mathrm{ml}$ of phosphate buffer solution PH6.4 was taken in dissolution vessel as media and warmed at 37 $\pm 0.5 \mathrm{C}$. the media was stirred at $50 \mathrm{Mrpm}$. $5 \mathrm{ml}$ sample from dissolution vessel as media was added maintain the shrink condition the sample was diluted up to $10 \mathrm{ml}$ and absorbance of these solution measured at $237 \mathrm{~nm}$ using the equation obtained from a standard calibration curve . Finally graph was plotted between time in $\mathrm{X}$ axis and cumulative percentage drug release in y axis.

\subsection{Drug release kinetics ${ }^{6}$}

The dissolution data obtained were fitted into following kinetic model. This was to determine the mechanism of drug release.

\section{Zero-Order Kinetics:}

Zero order as cumulative amount of drug released vs. time, $\quad \mathbf{C}=\mathbf{K ~ O} \mathbf{t}$

Where $K O$ is the zero-order rate constant expressed in units of concentration/time and $t$ is the time in hours. A graph of concentration vs time would yield a straight line with a slope equal to $K O$ and intercept the origin of the axes. ${ }^{28,29}$

\section{First Order Kinetics:}

The application of this model to drug dissolution studies used to describe absorption and/or elimination of drugs. To study the first order release rate kinetics the release rate data were fitted to the following equation

$$
\log \mathrm{Q}_{\mathrm{t}}=\log \mathrm{Q}_{0}+\mathrm{K}_{1} \mathrm{t} / 2.303
$$

$\mathrm{Q} t$ is the amount of drug released in time $\mathrm{t}$ Q0 is the initial amount of drug in the solution $\mathrm{K} 1$ is the first order release constant.

\section{Higuchi Model:}

Higuchi developed several theoretical models to study the release of water soluble and low soluble drugs incorporated in semi-solid and/or solid matrixes. Mathematical expressions were obtained for drug particles dispersed in a uniform matrix behaving as the diffusion media, the equation is $\quad Q_{t}=K H . t^{1 / 2}$

Qt is the amount of drug released in time $\mathrm{t} K \mathrm{KH}$ is Higuchi dissolution constant. Higuchi describes drug release as a diffusion process based in the Fick's law, square root time dependent. ${ }^{30,31}$

\section{Korsmeyer and Peppas Model:}

This model is generally used to analyze the release of pharmaceutical polymeric dosage forms, when the release mechanism is not well known or when more than one type of release phenomena could be involved.

$$
\mathrm{Mt} / \mathrm{M}=\mathrm{K} \cdot \mathrm{t}^{\mathrm{n}}
$$

$\mathrm{Mt} / \mathrm{M}$ is the fraction of drug release $\mathrm{K}$ is the release constant 
$\mathrm{t}$ is the release time $n$ is the diffusion exponent for the drug release that is dependent on the shape of the matrix dosage form.

Where $\mathrm{Mt} / \mathrm{M} \infty$ is the fractional solute release, $t$ is the release time, $K$ is a kinetic constant characteristic of the drug/polymer system, and $n$ is an exponent that characterizes the mechanism of release of tracers. For cylindrical matrix tablets, if the exponent $n=0.45$, then the drug release mechanism is Fickian diffusion, and if $0.45<n<0.89$, then it is non-Fickian or anomalous diffusion. An exponent value of 0.89 is indicative of Case-II Transport or typical zero-order release. ${ }^{32}$

\subsection{Polymer Swelling or Water Uptake studies}

The swelling behaviour of batches F2, F3, was studied. The tablets $(n=3)$ were kept in Petri dish containing $25 \mathrm{ml}$ distilled water at $37 \pm 2^{\circ} \mathrm{C}$ at selected time points, the tablets were withdrawn, wiped with tissue paper, and weighed. The percent water uptake by the tablet was calculated using the following formula:

Percentage water uptake $=100 \times[\mathrm{Wt}-\mathrm{W} 0 / \mathrm{W} 0]$

Where, Wt was weight of tablet at time $\mathrm{t}$ and $\mathrm{W} 0$ was initial weight of the tablet

\section{RESULT AND DISCUSSION}

\subsection{Preformulation studies}

The drug sample was evaluated for its colour and odour.

Table 2: Identification of Drug

\begin{tabular}{|l|l|l|}
\hline S. No & Parameter & drug \\
\hline 1 & Color & White \\
\hline 2 & Odour & odourless \\
\hline $\mathbf{3}$ & Taste & tasteless \\
\hline 4 & Appearance & Crystalline powder \\
\hline
\end{tabular}

\subsection{Determination Melting point:}

Melting point of the drug sample was determined by capillary method by using melting point apparatus.

Table 3: Melting Point of Pure Drug

\begin{tabular}{|l|l|l|}
\hline S. No & Reported M.P. & Observed M.P. \\
\hline 1 & $2^{222-226^{0}} \mathrm{c}$ & $2^{222-224^{0}} \mathrm{c}$ \\
\hline
\end{tabular}

\subsection{Solubility study:}

The solubility of the metformin HCL was determined by adding excess amount of drug in the solvent and equilibrium solubility was determined by taking supernated and analyzing it on shimadzu uv, double beam spectrophotometer the solubility of the metformin HCL was found to be slightly soluble in water and freely soluble in acetone.

Table 4: Solubility of metformin HCL in different solvent

\begin{tabular}{|l|l|l|l|}
\hline S. No & Medium found & \% found & Mg/100ml \\
\hline 1 & Water & $99.58 \%$ & 99.58 \\
\hline 2 & $0.1 \mathrm{~N}$ HCL & $100.10 \%$ & 100.10 \\
\hline 3 & $\begin{array}{l}\text { Phosphate } \\
\text { buffer ph(6.8) }\end{array}$ & $99.65 \%$ & 99.65 \\
\hline
\end{tabular}

\subsection{Preliminary Phytochemical Screening of Isolated Mucilage}

The Phytochemical screening of natural mucilage confirmed polysaccharides in nature [Table 5]. The physicochemical and microbiological properties of CTM were determined. The CTM Completely soluble in warm water, swelling index, viscosity obtained $33 \%$ and 20 $100 \mathrm{cps}$. The $\mathrm{pH}$ of the mucilage was found to be 5.6-6.5 were very near to neutral it may be less irritating on gastrointestinal tract and hence gum is suitable for uncoated tablet.

Table 5: Preliminary Phytochemical Screening of Isolated Mucilage

\begin{tabular}{|l|l|c|}
\hline S.No & Active constituent & CTM mucilage \\
\hline 1 & Carbohydrate & + \\
\hline 2 & Protien & - \\
\hline 3 & Flavanoids & - \\
\hline 4 & Tannins & - \\
\hline 5 & Saponins & - \\
\hline 6 & Sterol & - \\
\hline 7 & Alkaloids & - \\
\hline 8 & Terpenoids & - \\
\hline 9 & Protien & + \\
\hline 10 & Starch & - \\
\hline 11 & Fats & + \\
\hline \multicolumn{2}{|c|}{+ present, - absent } \\
\hline
\end{tabular}

Table 6: physicochemical properties of CTM mucilage

\begin{tabular}{|l|l|c|}
\hline S. No. & \multicolumn{1}{|c|}{ Parameter } & Result \\
\hline 1 & Appearance & Yellow white powder \\
\hline 2 & Solubility & Soluble in cold water and hot water forming viscous colloidal solution \\
\hline $\mathbf{3}$ & Swelling index $(\%)$ & $33.0 \pm 0.15$ \\
\hline $\mathbf{4}$ & $\mathrm{pH}$ & $5.5-6.5$ \\
\hline $\mathbf{5}$ & Hot viscosity $(1.0 \% \mathrm{w} / \mathrm{v}$ solution) & $20-100 \mathrm{cps}$ \\
\hline
\end{tabular}

All values are mean \pm S.D. for $n=3$

Table 7: Physicochemical properties of dried mucilage

\begin{tabular}{|l|l|l|l|}
\hline S.No & \multicolumn{1}{|c|}{ Properties } & Result & Type of flow \\
\hline 1 & Angle of repose & 25 & Good flow \\
\hline 2 & Bulk density & $0.600 \pm 0.05$ & Good \\
\hline 3 & Tapped density & $0.625 \pm 0.04$ & Good \\
\hline 4 & Compressibility index & $7.97 \pm 0.78$ & Excellent \\
\hline
\end{tabular}

All values are mean \pm S.D. for $n=3$ 


\subsection{FTIR spectrum of metformin HCL}

FTIR spectroscopy was performed for the identification of pure drug. The spectra was obtained from the FTIR spectrometer at the wavelength from $4000 \mathrm{~cm}^{-1}$ to 400 $\mathrm{cm}^{-1}$ is present at figure no and the characteristic peaks which was obtained is present in table no.

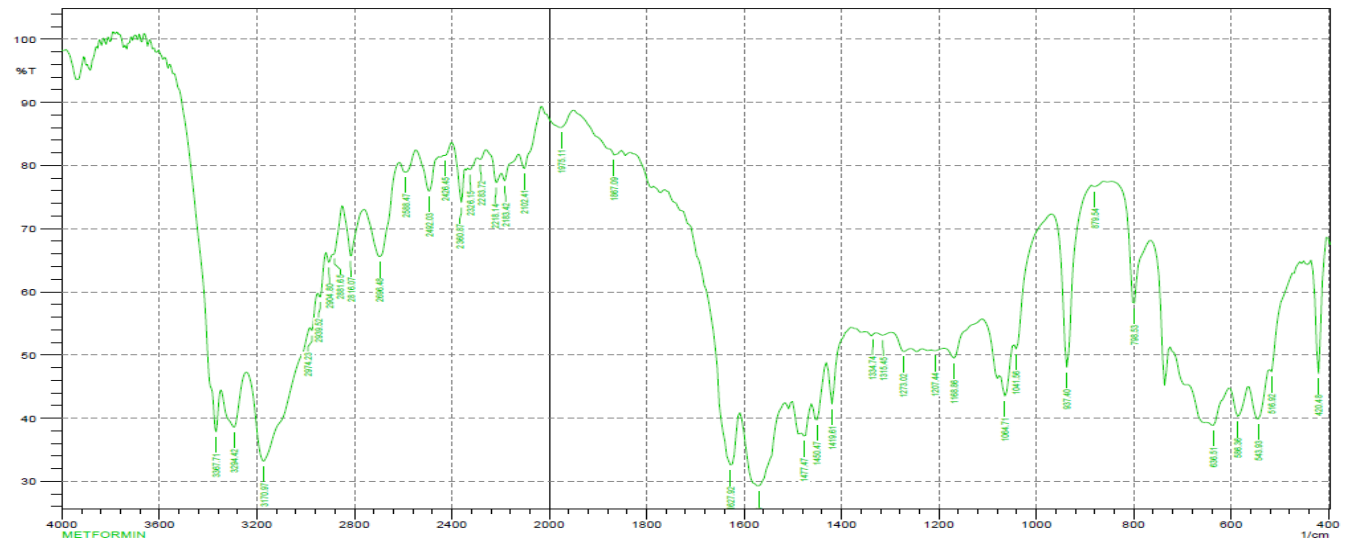

Figure 1: FTIR Spectra of Pure Drug Sample of Metformin HCL

Table 8: Comparison of reference spectrum with drug sample

\begin{tabular}{|l|l|l|}
\hline FTIR Band of METFORMIN HCL & FTIR Band Of Drug Sample & Functional Group \\
\hline 3370 & 3367.71 & NH- \\
\hline 3290 & 3294.42 & NH- \\
\hline 3174 & 3170.97 & C-H \\
\hline 1420 & 1418 & C-H \\
\hline 1477 & 1470.47 & C-H \\
\hline
\end{tabular}

\subsection{FTIR Spectra of CTM}

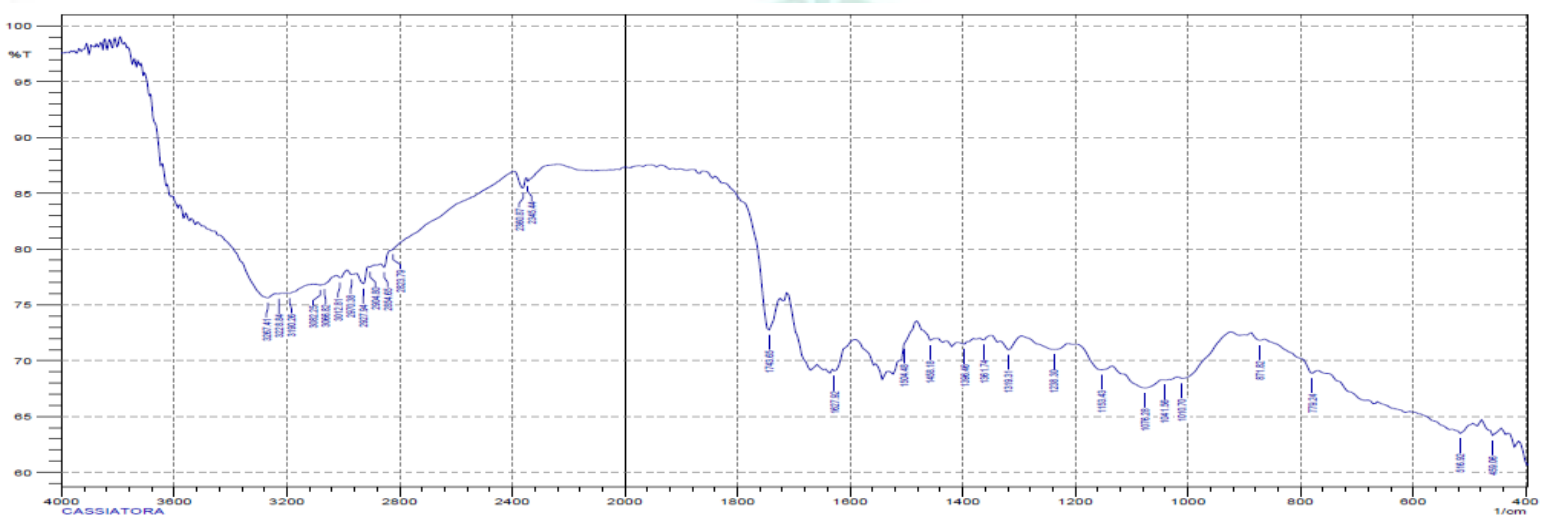

Figure 2: FTIR Spectra of CTM

Drug - excipients compatibility study:

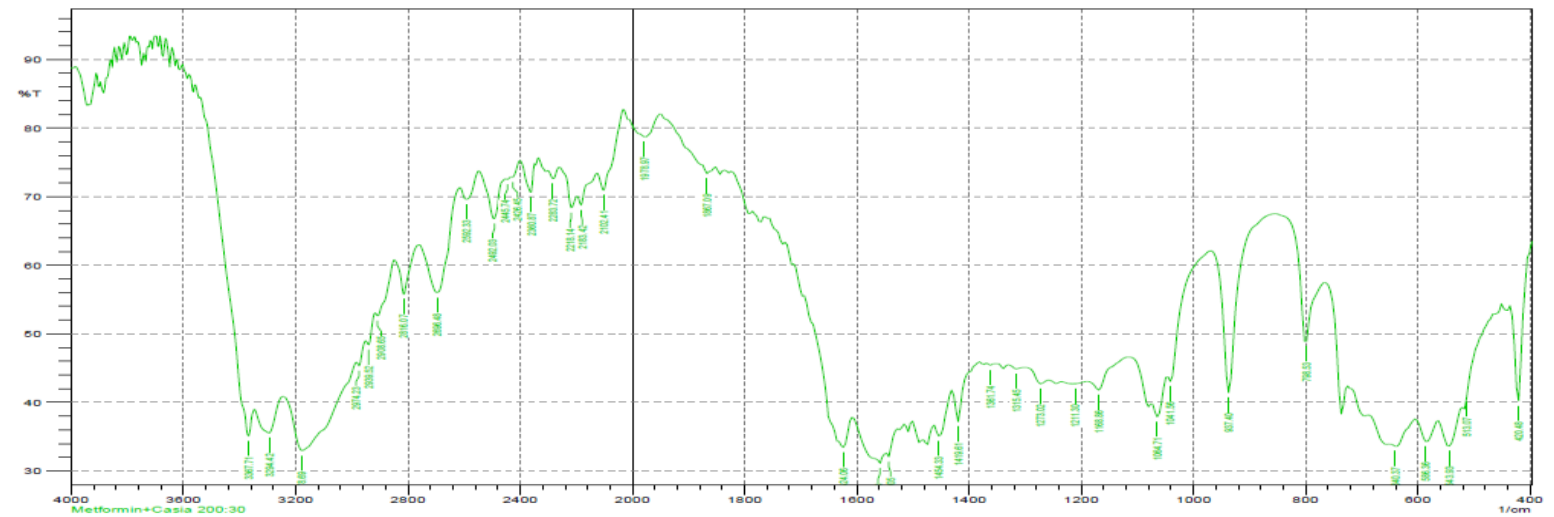

Figure 3: FTIR Spectra Ratio of CTM and Metformin HCL 


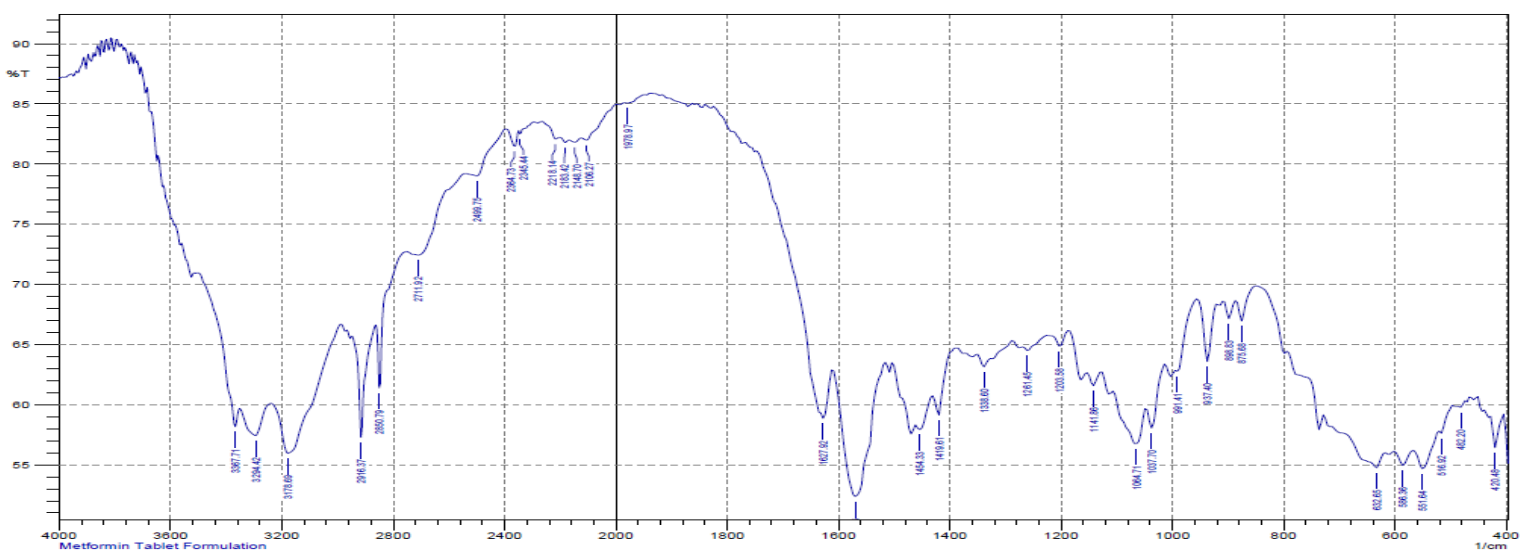

Figure 4: FTIR spectra of Metformin HCL tablet formulation

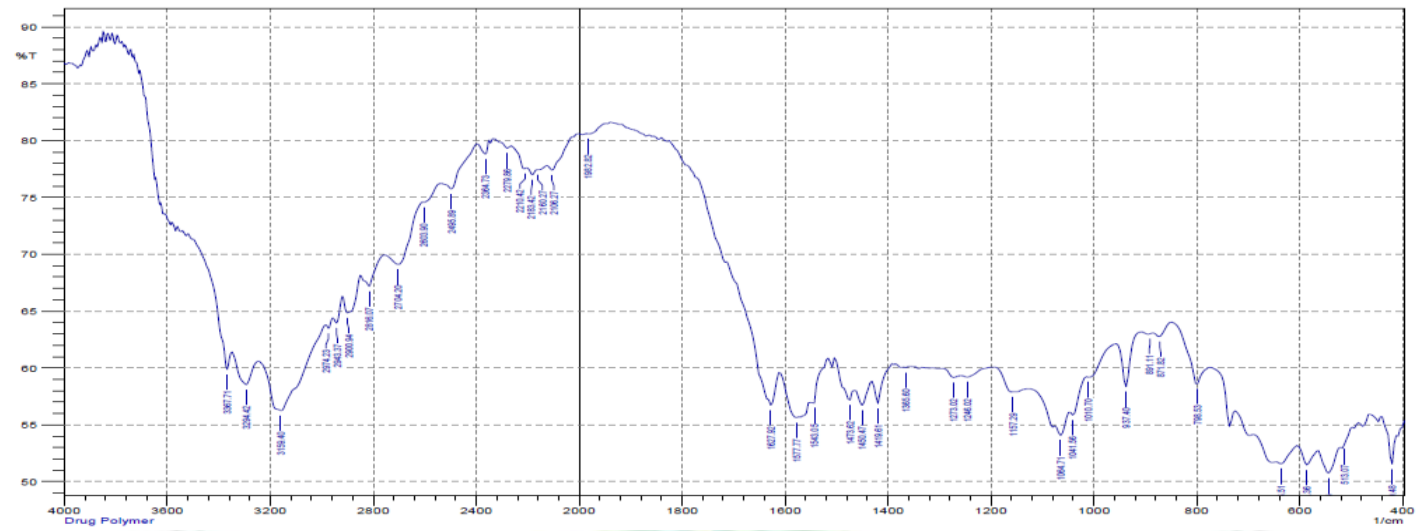

Figure 5: Drug - polymer compatibility study

Table 9: FTIR Interpretation of Pure Drug with Excipients

\begin{tabular}{|l|l|l|l|}
\hline \multirow{2}{*}{$\begin{array}{l}\text { FT-IR band of drug } \\
\text { sample }\left(\mathbf{c m}^{-\mathbf{1}}\right)\end{array}$} & \multicolumn{3}{|l|}{ FT-IR band of different formulaton $\left(\mathbf{c m}^{-\mathbf{1}}\right)$} \\
\cline { 2 - 4 } & F1 & F2 & F3 \\
\hline 3367.71 & 3367.71 & 3367.71 & 3368.96 \\
\hline 3294.42 & 3295.06 & 3295.06 & 3295.06 \\
\hline 1470.47 & 1447.23 & 1447.23 & 1447.23 \\
\hline
\end{tabular}

3.7 Standard calibration curve of Metformin HCL:

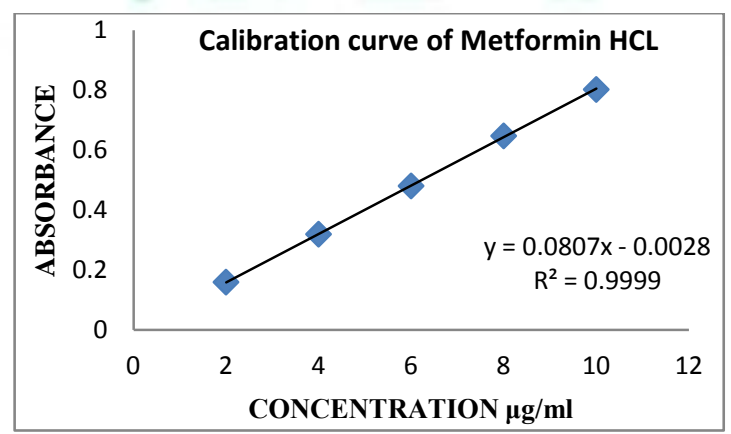

Figure 6: Standard Calibration Curve of Metformin HCL in Phosphate Buffer Ph 6.8

Table 10: Preformulation Evaluations of Metformin HCL Granules

\begin{tabular}{|c|c|c|c|c|c|c|}
\hline S. No & $\begin{array}{c}\text { Formulation } \\
\text { code }\end{array}$ & $\begin{array}{c}\text { Bulk Density } \\
(\mathbf{g} / \mathbf{m l}) \pm \text { S.D }\end{array}$ & $\begin{array}{c}\text { Tapped Density } \\
(\mathbf{g} / \mathbf{m l}) \pm \text { S.D }\end{array}$ & $\begin{array}{c}\text { Compressibility } \\
\text { Index }(\boldsymbol{\%}) \pm \text { S.D }\end{array}$ & $\begin{array}{c}\text { Hausner's } \\
\text { Ratio } \pm \text { S.D }\end{array}$ & $\begin{array}{c}\text { Angle of repose } \\
\pm \text { S.D }\end{array}$ \\
\hline 1 & F-1 & $0.547 \pm 0.018$ & $0.55 \pm 0.57$ & $7.33 \pm 3.550$ & $1.07 \pm 0.0416$ & $27.9 \pm 1.34$ \\
\hline 2 & F-2 & $0.54 \pm 0.0208$ & $0.586 \pm 0.011$ & $7.33 \pm 3.55$ & $1.253 \pm 0332$ & $26.40 \pm 0.70$ \\
\hline 3 & F-4 & $0.53 \pm 0.0251$ & $0.533 \pm 0.057$ & $6.9 \pm 7.078$ & $1 \pm 0.149$ & $26.55 \pm 0.915$ \\
\hline 4 & F-11 & $0.53 \pm 0.0264$ & $0.556 \pm 0.053$ & $5.58 \pm 6.42$ & $0.97 \pm 0.110$ & $27.01 \pm 0.455$ \\
\hline
\end{tabular}


Table: 11 Evaluation of Metformin HCL Tablet

\begin{tabular}{|l|l|l|l|l|l|}
\hline Formulation & $\begin{array}{l}\text { Thickness } \\
(\mathbf{m m})\end{array}$ & $\begin{array}{l}\text { Hardness } \\
\left(\mathbf{k g} / \mathbf{c m}^{\mathbf{2}}\right)\end{array}$ & $\begin{array}{l}\text { Friability } \\
(\mathbf{\%})\end{array}$ & $\begin{array}{l}\text { Average } \\
\text { weight(mg) }\end{array}$ & $\begin{array}{l}\text { Weight } \\
\text { variation }\end{array}$ \\
\hline F1 & $5.85 \pm 0.045$ & $6 \pm 0.854$ & $0.146 \pm 0.08$ & $506.1 \pm 367$ & Pass \\
\hline F2 & $5.73 \pm 0.06$ & $6.4 \pm 0.96$ & $0.109 \pm 0.038$ & $503.1 \pm 1.95$ & Pass \\
\hline F3 & $5.81 \pm 0.102$ & $5.66 \pm 0.51$ & $0.105 \pm 0.046$ & $506.1 \pm 3.66$ & Pass \\
\hline F4 & $5.79 \pm 0.08$ & $6.26 \pm 0.90$ & $0.146 \pm 0.087$ & $503.2 \pm 2.05$ & Pass \\
\hline
\end{tabular}

All values are mean \pm S.D. for $n=3$

\subsection{Drug Content}

Table 12: Drug Content of Different Formulation

\begin{tabular}{|l|l|l|}
\hline S.No & Formulation code & Drug contant (\%) \\
\hline 1 & F1 & 99.89 \\
\hline 2 & F2 & 99.53 \\
\hline 3 & F3 & 99.44 \\
\hline
\end{tabular}

Among the different formulation the drug content of tablet $99.53 \%$ of metformin HCL $500 \mathrm{mg}$.
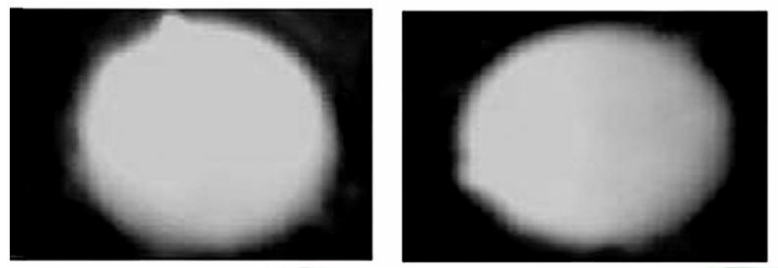

Figure 7: After 3 Hours of Swelling (F1-F3)
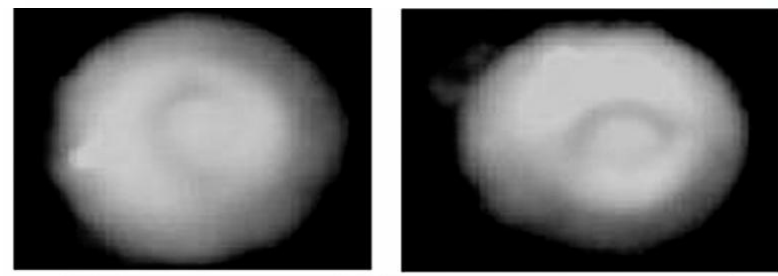

Figure 8: After 5 hours of swelling (F2-F3)
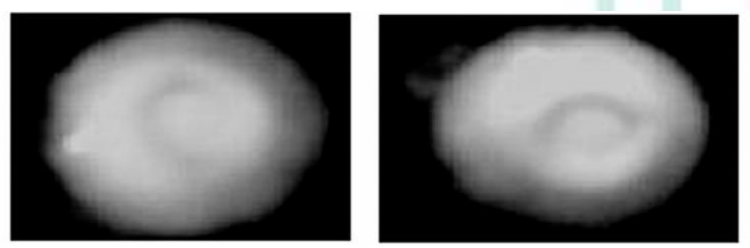

Figure 9: After 10 Hours of Swelling (F2-F3)

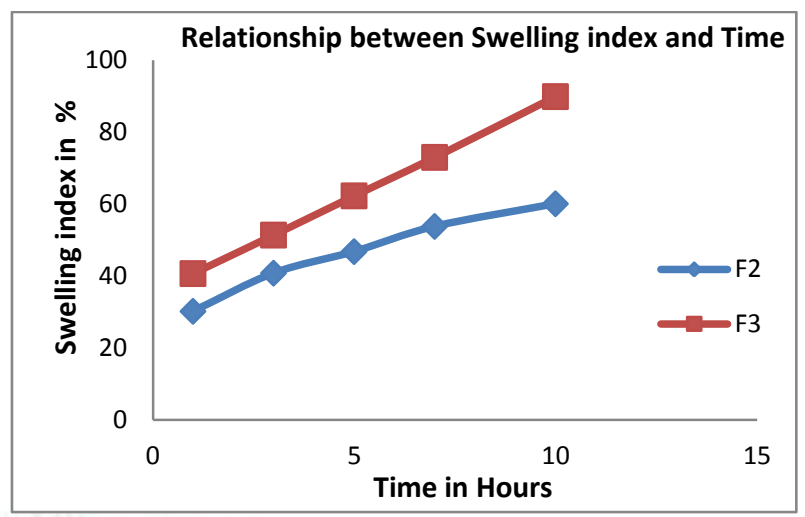

Figure 10: Relationship between Swelling index and Time (Batch F2 to F3)

3.10 In vitro drug release: in vitro drug release of different formulation is shown in Figure 11.

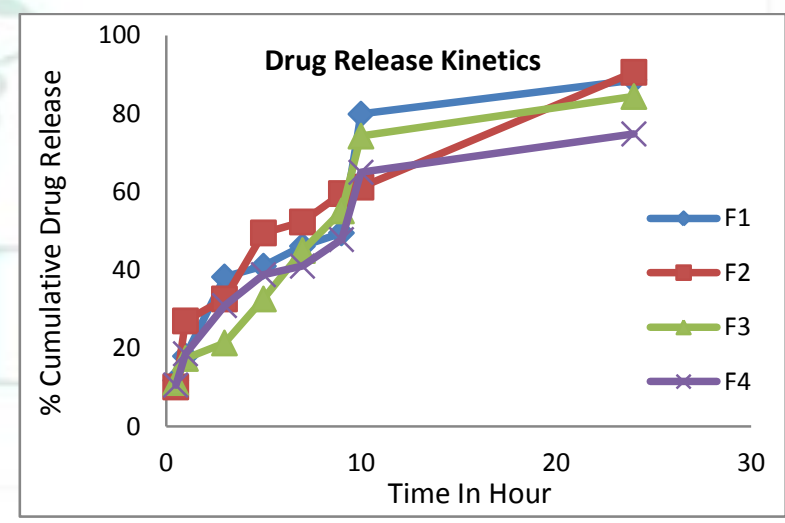

Figure 11: drug release kinetics of Different Formulation

3.11 Drug release kinetics of different formulation:-

Table 13: Drug Release Kinetics of Different Formulation

\begin{tabular}{|c|c|c|c|c|}
\hline F. Code & $\begin{array}{c}\text { Zero order } \\
\mathbf{R}^{2}\end{array}$ & First Order $\mathbf{R}^{2}$ value & Higuchi Equation $\mathbf{R}^{2}$ & $\begin{array}{c}\text { Korsmeyer Modle } \mathbf{R}^{2} \\
\text { Values }\end{array}$ \\
\hline F1 & 0.856 & 0.824 & 0.838 & 0.756 \\
\hline F2 & 0.900 & 0.900 & 0.976 & 0.566 \\
\hline F3 & 0.951 & 0.951 & 0.958 & 0.550 \\
\hline $\mathrm{F} 4$ & 0.927 & 0.926 & 0.920 & 0.729 \\
\hline
\end{tabular}




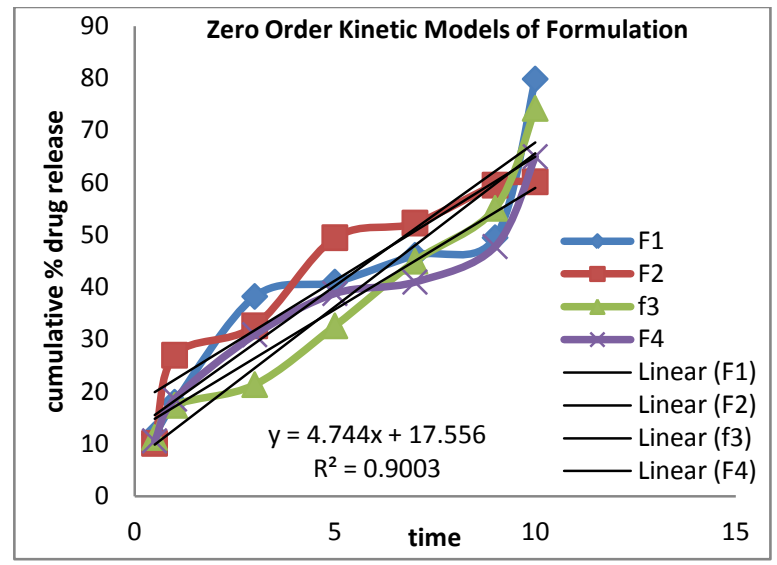

Figure 12: Zero Order Kinetic Models of Formulation F1to F4

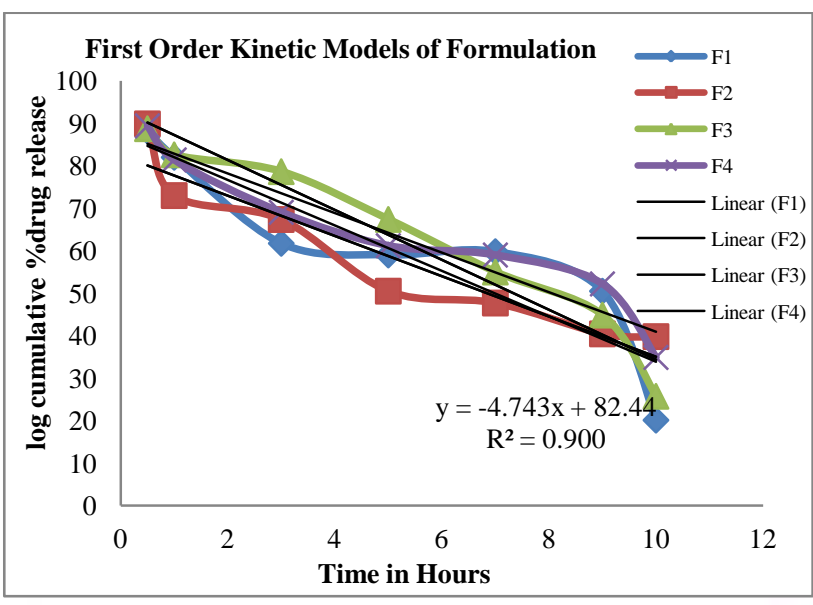

Figure 13: First Order Kinetic Models of Formulation of F1, F2, F3 and F4

\subsection{Accelerated stability studies}

The stability study of optimized batch was carried out at $25^{\circ} \mathrm{C} / 60 \% \mathrm{RH}, 30^{\circ} \mathrm{C} / 65 \% \mathrm{RH}$ and $40^{\circ} \mathrm{C} / 75 \% \mathrm{RH}$ as per $\mathrm{ICH}$ guidelines. The tablets of all formulation were found to be stable at such condition and other parameters were found to be unaffected and were under pharmacopoeial limits.

\section{DISCUSSION}

In preformulation studies drug sample was procured and identified by comparing the FTRI SPECTRUM with standard reference, and the sample have the entire peak according to standard reference for the identification of the drug their melting point and solubility test was determined in which sample result was performed according to standard. The drug compatibility study was also performed with the help of FTIR, and there not any chemical interaction was found between drug and excipients at any formulation. Bulk density of the developed formulation $\mathrm{F} 1$ to $\mathrm{F} 4$ varied from $0.53 \pm 0.0251 \mathrm{gm} / \mathrm{ml} 0.54 \pm 0.0208$, the tapped densities were varied from in the range of $0.533 \pm 0.0577$ to $0.586 \pm 0.011$ the difference between tapped density and bulk density were near about same of all formulation except $\mathrm{F} 4$ formulation. The compressibility index value was found to be range of $5.58 \pm 6.42$ to $7.33 \pm 3.550$. these finding indicated that the powder mixture exhibited

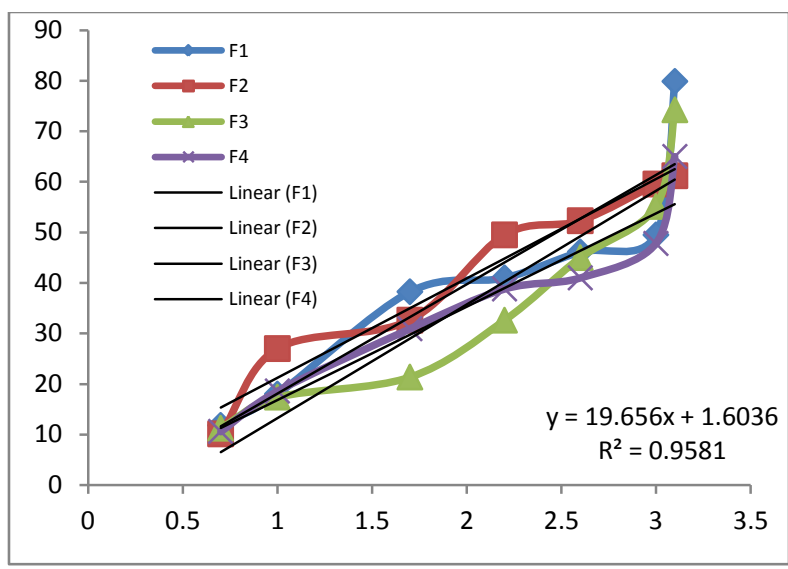

Figure 14: Higuchi Models of Formulation F1 to F4

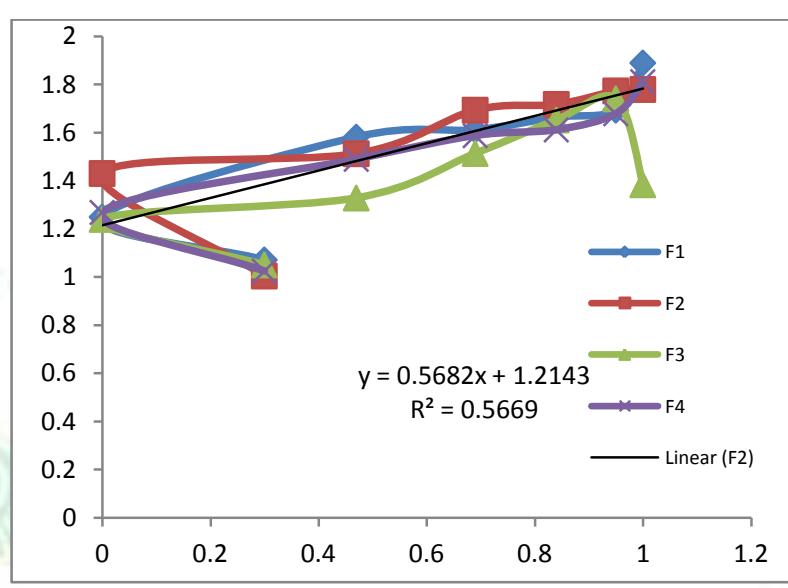

Figure 15: Korsmeyes Peppas Kinetic Models of Formulation F1, F2, F3 and F4

Excellent flow properties .The result of Hausner's Ratio were ranged from $0.97 \pm 0.110$ to $1.253 \pm 0332$, which indicate good flow properties of F3 formulation and F2 formulation good flow properties. The angle of repose was ranged between $26.40 \pm 0.70$ to $27.9 \pm 1.34$, which indicates good flow property of powder.Thickness of the developed formulation varied from $5.73 \pm 0.06 \mathrm{~mm}$ to $5.85 \pm 0.045$, which was uniformly throughout the batches and within the permissible limit hardness varied from $5.66 \pm 0.51$ to $6.4 \pm 0.96 \mathrm{~kg} / \mathrm{cm}^{2}$ which indicates tablets possess sufficient strength. The friability of all formulation was found to be a minimum from $0.146 \pm 0.08$ to $0.109 \pm 0.038 \%$. Among all the formulation the friability of F1, F2, F3, F4 batch were good friability. The average weight of twenty tablets was calculated for each batch which varied from $503.1 \pm 1.95$ to $506.1 \pm 367 \mathrm{mg}$, the percent deviation of all the formulations comply with weight variation test.In the formulation no F-1 EC 20\% and HPMC 10\%, xanthan gum $4 \%$ was using in CTM $6 \%$, as decreased the concentration of polymer the release rate increase and only $80 \%$ drug release in $10 \mathrm{hrs}$. In the preparation of the tablets (F2), combination of HPMC and ethyl cellulose was used in 3 xanthane gum, Microcrystalline cellulose, Cassia tora, talc and magnesium stearate was used, and tablet were prepared by wet granulation technique, in which $500 \mathrm{mg}$ strength tablet was prepared with help of $9 \mathrm{~mm}$ diameter punch size, and 
the thick ness was found to be $6.5 \mathrm{~mm}$, several batch were prepared to sustained the release of drug.

When dissolution study was performed for the tablet, due to presence of xanthane gum HPMC ,EC and CTM using tablet was hydrated and swelled upon contact with aqueous media and released rate $\mathrm{F}-2$ and $\mathrm{F}-3$ formulation $62-74.25 \%$ drug release in $10 \mathrm{hrs}$ the release kinetics was determined for the batches and formulation followed the higuchi model. The calculated regression coefficients showed a higher $r^{2}$ value with higuchi model $\left(r^{2}=0.958\right)$. Hence the release data of the Tablet obeyed Higuchi model and release the drug diffusion mechanism. For the above study it was

\section{REFERENCES}

1. Khullar P, Khar RK, Agarwal SP. Evaluation of Guar Gum in the Preparation of Sustained release Matrix Tablets. Drug Dev Ind Pharm. 1998; 24:1095-9.

2. Lee Vhl, Controlled Drug Delivery Fundamentals and Applications: Introduction, Marcel Dekker, (2nded) Inc, and New York. 1987:29.

3. P.L. Soni, R. Pal, Trends In Carbohydrate Chemistry, 1996; 2:33-44

4. Leon, Shargel (1994), "Comprehensive Pharmacy Review", 2nd Edition, Harwal Publishing, London, 101-104.

5. Nokano M, Ogata A. In Vitro Release Characteristics of Matrix Tablets: Study Of Karaya Gum and Guar Gum as Release Modulators. Ind. J. Pharm. Sc. 2006; 68(6):824-826.

6. Colombo P, Bettini R, Peppas Na. Drug Diffusion Front Movement Is Important In Drug Release Control Forms Well Able Matrix Tablets. Ind. J. Pharm. Sci.1985; 84:991-7

7. Banker Gs and Anderson Nr. The Theory and Practice of Industrial Pharmacy: Tablet, Lachman, (3rded) Varghese Publishing House, Bombay, 1990, 293-303.

8. Singh K, Walia M, Agarwal G, Harikumar S. Osmotic pump drug delivery system: a noval approach. Journal of Drug Delivery and Therapeutics, 2013; 3(5):156-162. doi:10.22270/jddt.v3i5.636

9. Garg A, Gupta M. Mouth Dissolving Tablets: A Review. Journal of Drug Delivery and Therapeutics, 2013; 3(2):207-214. doi:10.22270/jddt.v3i2.458

10. Kapoor D. Fabrication and characterization of non steroidal anti-inflammatory alginate beads for sustained release using natural polymer. Journal of Drug Delivery and Therapeutics, 2017; 7(2):77-80. doi:10.22270/jddt.v7i2.1401

11. Brahmankar D.m and Jaywalk Sb.Biopharmaceutics and Pharmacokinetics Pharmacokinetics, (2nd Ed) Vallabh Prakashan, Delhi, 2009, 399-401.

12. Lee Vhl. Controlled Drug Delivery Fundamentals and Applications: Influence of Drug Properties On Design, (2nded) Marcel Dekker, Inc, New York. 1987:16-25.

13. Vishvakrama P, Sharma S. Liposomes: An Overview. Journal of Drug Delivery and Therapeutics, 2014; 0:47-55. doi:10.22270/jddt.v0i0.843

14. Keshari A, Tripathi D, Srivastava A, Vishwas R. Formulation and evaluation of effervecent floating tablets of antidiabetic drug. Journal of Drug Delivery and Therapeutics, 2015; 5(6):43-55. doi:10.22270/jddt.v5i6.1176

15. Kumar Raj, Kohli Kamlesh, Kajal HL, A study of drug prescribing pattern and cost analysis among diabetic patients in a tertiary care teaching institute in north India'. Journal of Drug Delivery and Therapeutics, 2013; 3(2):56-61. doi:10.22270/jddt.v3i2.431 conclude that sustained release matrix tablet using CTM can be prepared successfully in industrial scale.

\section{CONCLUSION}

The present research work was undertaken with an abjective to reparation, formulation and evaluation metformin HCL tablet by altering polymer and CTM Mucilage (HPMC, EC, XANTHAN GUM AND CASSIA TORA MUCILAGE) as a trial, for treatment of Antidiabetic .primarily were prepared using wet granulation technique, and were evaluated as pharmacopoeial specification experimental work till done.

16. Nokano M, Ogata A. Invitro release characteristics of matrix tablets: Study of karaya gum and guar gum as release modulators. Ind. J. Pharm. Sc. 2006; 68(6):824-826.

17. C.K. Kokate, Practical Pharmacognosy, 4th Ed., Vallabh Prakashan, Delhi, 2006, 123.

18. Kirtiker KR, Basu BD, Indian Medicinal Plants, Volume II, Second Edition. Jayyed Press, New Delhi 1975; 30-45.

19. Anonymous, Ayurvedic Pharmacopoeia of India, Part-II, Vol.I, 1st Ed., Ministry of Health And Family Welfare Department of Indian System Of Medicine \& Homoeopathy, New Delhi, India, 1999, 41.

20. Indian Pharmacopoeia Ministry of Health and Family Welfare. Delhi: Controller of Publications; 1996

21. Rao N, Laharika M, Kistayya C. Design and development of simvastatin gastroretentive tablets for controlled release. Journal of Drug Delivery and Therapeutics, 2017; 7(1):30-36. doi:10.22270/jddt.v7i1.1353

22. Banker G.S., Rhodes C.T., Modern Pharmaceutics, Drug And Pharmaceutical Science, 2nd Edn, Dekker Marcel:501-527

23. Kumar S.K.P., Debjit B., Srivastava S., Paswan S., Dutta As., Sustained Release Drug Delivery System Potential, The Pharma Innovation. 2012; 1(2):48-60.

24. Remington: The Science and Practice Of Pharmacy, Published By: Wolter Kluwer Health (India): 2006; 21st Edn, Vol 1:939964.

25. Chugh I, Seth N, Rana AC, Gupta S, Oral Sustain Release Drug Delivery System: An Overview, International Research Journal of Pharmacy. 2012; 3(5):57-62.

26. Dir S., Badola A., Sharma D., Sustained Release Matrix Technology and Recent Advance in Matrix Drug Delivery System: A Review. International Journal of Drug Research Andtechnology, 2013; 3(1):12-20.

27. Lieberman H.A., Lachman L., Kanig J L., The Theory and Practice of Industrial Pharmacy, 3rd Edn, Published By: Varghese Publishing House:430-456

28. Banker G.S., Rhodes C.T., Modern Pharmaceutics, Drug and Pharmaceutical Science, 2nd Edn, Dekker Marcel: 501-527.

29. Dusane A.R., Gaikwad P.D., Bankar V.H, Pawar S.P., A Review on Sustain Release Technology, International Journal Research In Ayurvedic And Pharmacy. 2011; 2(6):1701-1708.

30. Gupta M.M., Ray B., A Review on: Sustained Release Technology, International Journal Of Therapeutic Applications. 2012; (8):1-23.

31. Ratnaparkhi M.P., Gupta J.P., Sustained Release Oral Drug Delivery System - An Overview International Journal of Pharma Research \& Review. 2(3):11-21, 2013

32. Vyas S.P, Khar R.K., Controlled Drug Delivery Concept and Advances, 2nd Edn Delhi: 2012; 1-53. 